\title{
A IMPORTÂNCIA DA LEITURA NA FORMAÇÃO CIDADẢ NO ENSINO FUNDAMENTAL II
}

Flaviane Gonçalves Corrêa ${ }^{1}$ Laís Lagreca de Carvalho ${ }^{2}$

\section{Apresentação}

A partir das observações realizadas na disciplina de Estágio Supervisionado II de Língua Portuguesa, percebemos que as atividades de leitura feitas pelos alunos necessitavam acontecer de forma mais crítica, a fim de que a leitura não se resumisse a uma simples decodificação do código linguístico.

Dessa maneira, apresentamos neste trabalho uma intervenção didática que teve como objetivo, a partir de gêneros textuais diversos, tratar de uma temática relevante para a formação cidadã dos alunos, a temática da busca pelo corpo perfeito, uma vez que a exposição da própria imagem está cada vez mais presente na vida das pessoas. Optamos por partir de um gênero textual muito comum na Antiguidade Clássica, o mito, para mostrar que questões relacionadas à vaidade estão presentes há muito tempo na sociedade. Essa intervenção foi aplicada em uma turma de oitavo ano do Ensino Fundamental.

\section{Caracterização da escola}

A escola em que o estágio se desenvolveu foi fundada no ano de 2009, é uma instituição de ensino estadual, vinculada à Secretaria de Educação de Minas Gerais, localizada na região oeste da cidade de Juiz de Fora, Minas Gerais.

Atualmente, a escola ministra cursos de Ensino Fundamental, Ensino Médio e Educação de Jovens e Adultos (EJA) ${ }^{3}$. Por estar localizada nas proximidades da Universidade Federal de Juiz de

\footnotetext{
${ }^{1}$ Graduada em Letras na Universidade Federal de Juiz de Fora - flavianegcorrea@gmail.com

2 Mestranda em Linguística pela Universidade Federal de Juiz de Fora -laislagreca@gmail.com

${ }^{3}$ Tal informação foi extraída do site "escol.as", disponível no link <http://www.escol.as/168910-ee-nyrce-villaverde-coelho-de-magalhaes>. Acesso em: 19 de junho de 2016.
} 
Fora, essa instituição recebe grande número de estagiários de diferentes cursos de licenciatura oferecidos pela UFJF.

\section{Fundamentação teórica}

Com base nas reflexões realizadas ao longo de duas oficinas ${ }^{4}$ presentes na grade do curso de Letras da UFJF, ambas de caráter prático, pudemos refletir sobre a importância de se trabalhar a cultura clássica nas escolas e a importância da leitura na formação de leitores críticos na educação básica.

As discussões que proporcionaram o primeiro recorte para a intervenção didática, referente ao trabalho com a cultura clássica, foram pautadas, no artigo: Cultura Clássica e Ensino: uma reflexão sobre a presença dos gregos e latinos na escola (FORTES; MIOTTI, 2014).

Para os autores desse artigo, ainda hoje há quem pense que a pesquisa voltada à cultura clássica está associada a um grupo específico de especialistas que trabalham sozinhos com língua e textos antigos nas universidades. A proposta do referido artigo se opõe a essa concepção, "buscando apontar novas perspectivas para a inserção dos Estudos Clássicos na prática cotidiana de ensino e aprendizagem nas escolas brasileiras" (FORTES; MIOTTI, 2014, p.154).

Segundo os autores, uma obra "clássica", independentemente do tempo em que foi produzida, permanece na cultura. Ela é considerada inesquecível, pois sobrevive na memória, coletiva ou individual, contribuindo para cultura da sociedade, direta ou indiretamente.

Em vista disso, os textos clássicos, principalmente, os antigos, além do efeito de imortalidade e permanência, são vistos como referenciais identitários atemporais, consagrados a maiores patrimônios imateriais da nossa cultura.

Os autores do artigo realizaram uma breve análise de documentos oficiais que regulamentam os curricula educacionais nos dias atuais, principalmente a LDB (Lei de Diretrizes e Bases/ Lei 9394/96) e os Parâmetros Curriculares Nacionais para o Ensino Fundamental (1998) e Médio (2000) e constataram "uma referência muito tímida à cultura clássica greco-romana em suas propostas para o ensino de língua portuguesa, literatura e humanidades" (FORTES; MIOTTI, 2014, p.154). Esses

\footnotetext{
${ }^{4}$ Oficina IX: Estudos Clássicos “Letras Clássicas na Escola” e Oficina VI: Estudos Linguísticos “A leitura em sala de aula".
} 
documentos abordam amplamente o modelo educacional vigente após as reformas educacionais, norteando o planejamento, a oferta e a execução de conteúdos disciplinares na Escola Básica, entretanto, desprezam a importância das matrizes clássicas da cultura brasileira, mesmo essas matrizes estando tão presentes no imaginário cultural contemporâneo.

Nesse sentido, para os autores, uma vez inserida a cultura clássica na escola, os tópicos da cultura greco-romana, a partir do repertório literário latino e grego, poderiam propiciar uma experiência relevante, dando ênfase à construção da identidade brasileira e enriquecendo o repertório cultural dos alunos. Valendo-se também para uma visão crítica dos elementos culturais presentes hoje, na mídia, nos filmes e na indústria de entretenimento de modo geral.

Com base na concepção apresentada sobre os textos clássicos, acreditamos que a inserção de um texto antigo permitiria um reconhecimento de valores atemporais, contribuindo para a formação de leitores críticos.

Tendo como ponto de partida um texto antigo, do poeta romano Ovídio, demos continuidade a nossa intervenção didática, com base nos Parâmetros Curriculares Nacionais (Brasil, 2002) e nos livros Oficina de leitura (KLEIMAN, 2013) e Ler e compreender: os sentidos do texto (KOCH; ELIAS, 2014).

É fato que a leitura tem extrema importância no cotidiano da sociedade contemporânea. As pessoas, desde pequenas, deveriam ser incentivadas a desenvolver o hábito da leitura. Como nem todas possuem o privilégio de ter o contato com a leitura no ambiente familiar, isso acaba ficando a cargo da escola, principalmente dos professores de Língua Portuguesa.

Segundo o PCN - Ensino Fundamental, é importante que o professor não planeje o trabalho da leitura em função de um aluno ideal, projetado por diversos livros didáticos, correndo o risco de transmitir algo que o aluno já sabe ou algo muito aquém de suas possibilidades.

No PCN - Ensino Fundamental há algumas sugestões didáticas para a formação de leitores, quais sejam: (i) leitura autônoma, o aluno tem a liberdade de ler textos que ele já possui alguma proficiência; (ii) leitura colaborativa, o professor lê um texto para a classe e faz perguntas sobre o mesmo, construindo, assim, o sentido do texto; (iii) leitura em voz alta pelo professor, o professor também pode ler em voz alta para os alunos, de acordo com a proficiência de leitura desses alunos; (iv) leitura programada, o sentido do texto é construído de forma compartilhada, reduzindo o "esforço" feito pelos alunos. Os alunos são provocados, pelo professor, com objetivo de construírem 
o sentido do texto; (v) leitura de escolha pessoal, o objetivo é a leitura em si. Nesse caso, os alunos escolheriam o que mais gostam de ler.

Além dessas, a noção de leitura apresenta diversas outras concepções. De acordo com Koch \& Elias (2014), uma concepção difundida tem foco no autor. O leitor, nessa concepção, tem um papel passivo, o texto apresenta uma única leitura e o papel do leitor é "captar" essa representação mental do autor. Nessa concepção, é comum frases como: "O que o autor quis dizer?". O texto, nessa concepção, é visto como um produto da representação mental do autor, o leitor pouco importa, com suas experiências e conhecimentos, para o sentido do texto.

Outra concepção possível tem foco no texto, sendo o sujeito "assujeitado" pelo sistema. Nessa concepção, a língua é vista como um código - instrumento de comunicação - o sujeito, determinado pelo sistema, desempenha o papel de decodificador. Para isso, ele deve apenas conhecer o código utilizado. Na concepção anterior era papel do leitor captar "o que o autor quis dizer", nessa concepção cabe ao leitor reconhecer o sentido das palavras e estruturas do texto.

Outra concepção possível é a interacionista, que tem como foco a interação autor-textoleitor. O sentido, nessa concepção, é construído com base na interação mútua, os sujeitos são vistos como atores (sujeitos ativos). A partir da leitura, dependendo de cada leitor, o sentido vai tomando outras formas com as especificidades de cada um.

Já com base no trabalho de Kleiman (2013), as concepções de leitura são apresentadas como: a leitura como decodificação que é vista como automática, nesse caso há um abismo entre ler e entender. A leitura não contribuiria em nada para a formação de mundo do aluno. Seria uma leitura superficial, em que o leitor passa os olhos sobre o texto e destaca o que está sendo pedido pelo professor.

Uma distinta concepção é a leitura como forma de avaliação, essa prática também inibe ao invés de promover a formação de leitores críticos. As aulas ficam reduzidas a leituras em voz alta. Porém quando o aluno é posto a ler em voz alta ele fica mais preocupado em pronunciar tudo corretamente do que em entender de fato o que está lendo.

Já a concepção autoritária de leitura trabalha como uma interpretação "autorizada" em que a individualidade do leitor é irrelevante. Essa concepção acredita numa só maneira de abordagem do texto. 
Outros conceitos estão atrelados à concepção do que é leitura. De acordo com Koch (2014), é necessário recorrer a três grandes conhecimentos: conhecimento linguístico; conhecimento enciclopédico; conhecimento interacional.

A prática de algumas dessas concepções acaba não permitindo a real interação entre professor e aluno. Geralmente, o professor apresenta um texto, sem ao menos perguntar aos alunos suas preferências e gostos, solicita uma leitura silenciosa - para que o aluno tenha a oportunidade de decodificar, e logo após realiza uma leitura em voz alta. Com isso, o professor pensa estar trabalhando a oralidade e a interpretação, a partir disso apresenta uma série de perguntas que ele julga pertinente ao que pretende trabalhar. Nesse caso, o aluno-leitor não tem voz e nem vez, funciona de modo automático, lendo e extraindo informações.

Uma concepção interessante é a interação autor-texto-leitor, o leitor ganha espaço, sua experiência de mundo é relevante na construção de sentido. O professor propõe que o aluno pense, reflita sobre o texto e não apenas reproduza automaticamente as informações decodificadas. Acreditamos que com isso a leitura passa a fazer sentido na vida de qualquer pessoa, principalmente na de nossos alunos.

\section{Descrição da experiência}

Com base na fundamentação teórica que nos serviu de apoio para a elaboração da presente intervenção didática, pudemos traçar um percurso de leitura que partisse de um texto pertencente à Cultura Clássica, um mito, perpassando outros gêneros. Assim, partimos de um tema relevante para a formação cidadã dos alunos, para que eles pudessem aprimorar o processo de leitura, ativando seus conhecimentos de mundo, dando espaço a uma leitura preocupada com a construção do sentido, colocando os alunos como agentes no processo de significação.

Para tratar do tema de exposição da imagem, que se relaciona à busca pelo corpo "perfeito", optamos por trabalhar com diversos gêneros textuais e, a fim de demonstrar que essa temática sempre esteve presente na vida das pessoas, optamos por ter como primeiro gênero textual um mito, o mito de "Eco e Narciso" do poeta romano Ovídio.

Antes de iniciar a leitura do texto, como parte do trabalho de pré-leitura, perguntamos aos alunos se eles já tinham ouvido falar do mito de "Eco e Narciso", se conheciam um desses personagens. Nesse momento, fomos surpreendidas por uma aluna que demonstrou profundo 
conhecimento sobre o mito, o que muito nos alegrou e permitiu que fizéssemos uma espécie de apresentação dos personagens que compõem a história (figuras como deuses e ninfas). Após esse diálogo, entregamos a eles uma imagem que retratava a pintura a óleo de John William Waterhouse de Eco e Narciso e falamos um pouco sobre a pintura.

Tendo sido realizada essa primeira etapa, partimos para a atividade de leitura do mito de Eco e Narciso, na qual os alunos mostraram-se muito interessados no enredo da narrativa, de modo que o silêncio teve protagonismo, contribuindo para que a atenção se voltasse para o que acontecia naquele momento.

Realizada a leitura, iniciamos as atividades de pós-leitura, perguntando o que eles entenderam do mito, se a ninfa Eco Ihes remontava a alguma ideia ("eco": repetição dos sons em lugares fechados e vazios) e o que acharam do comportamento de Narciso. Com essas perguntas pretendíamos levá-los a perceber que Narciso tinha um comportamento centrado em si mesmo, na sua beleza.

Para encerrar esse primeiro momento, entregamos uma imagem de uma releitura da pintura de Waterhouse, a fim de questionar os alunos o que mudou da primeira imagem para a segunda (a presença de um smartphone com a página de uma rede social no lugar do lago) e o que isso queria dizer, levando os alunos a entenderem o objetivo dessa releitura e o cultivo exagerado, que pode ser até mesmo perigoso, da autoimagem que as redes sociais podem potencializar.

Para o segundo momento, foi escolhido o texto "Narcisismo: A hora das estrelas", uma reportagem da década de 80, que trata do tema "narcisismo". Essa leitura teve como propósito levar aos alunos as diversas acepções do termo "narcisismo", além de demonstrar sua ligação com a mitologia clássica.

Após a leitura da reportagem, conversamos com os alunos sobre a temática do narcisismo e perguntamos a eles se esse tipo de comportamento dito "narcisista" aumentou ou diminuiu desde a época da publicação da reportagem e o que pode ter influenciado tal mudança. Nesse momento, os alunos puderam dizer o que pensavam sobre a grande exposição nas redes sociais e o que achavam disso, se concordavam ou não, de modo que foi possível mostrar-Ihes que não é necessário proibir o uso, mas usar de forma consciente e crítica as redes sociais. 
A fim de relacionar os dois primeiros momentos e verificar o entendimento dos textos e suas discussões, aplicamos uma atividade interpretativa referente aos dois textos (Anexo I), a qual foi realizada, corrigida e comentada em sala de aula.

No terceiro momento, foram escolhidos dois gêneros textuais: um artigo científico e uma tirinha. 0 primeiro texto, intitulado "Ditatura da estética: a busca pelo corpo perfeito" foi escolhido para que pudéssemos fazer questionamentos como: (i) qual a opinião de vocês sobre a busca pelo corpo perfeito? (ii) de onde vem essa ideia de que existe um corpo perfeito? (iii) corpo perfeito é sinônimo de saúde? (iv) para vocês, qual o papel da mídia nessa busca pelo corpo perfeito? Essa atividade de leitura gerou boas discussões, de modo que pudemos perceber que realmente a mídia cria estereótipos de beleza. Através da discussão do texto, tentamos combater a ideia estereotipada do que é ser belo e mostrar aos alunos que, muitas vezes, somos levados a acreditar que só há uma forma de sermos bonitos e aceitos na sociedade. Outro ponto relevante relacionado à preocupação com o "corpo perfeito", trazido no texto, tem a ver com as doenças causadas por essa busca incansável da perfeição imposta pela mídia.

Após a discussão do primeiro texto, passamos à leitura da tirinha, sobre a qual perguntamos o porquê de ela ser engraçada, a fim de verificar se eles conseguiam compreender o humor em um texto que conjuga linguagem verbal e não verbal, e perguntamos também quais são os dois conceitos de "corpo perfeito" presentes no texto.

No quarto e último momento, elegemos duas reportagens que falam sobre os perigos das famosas selfies. Essas reportagens foram escolhidas pela sua relação com a temática abordada ao longo da intervenção e pelo uso que os próprios alunos fazem das selfies, que são práticas comuns nas redes sociais. Nosso objetivo foi, a partir da leitura desses textos, mostrar aos alunos os perigos advindos dessa necessidade excessiva de exposição da vida, necessidade que tira até mesmo a lucidez da pessoa, levando-a a perigos fatais. Além do perigo fatal retratado pelas reportagens, as selfies e as fotografias de modo geral, divulgadas na internet, podem envolver outros tipos de riscos, como a divulgação de informações pessoais, por exemplo.

Após a leitura dessas reportagens, entregamos aos alunos um questionário (Anexo II) sobre os textos, que visa não só a verificação do entendimento do texto por parte dos alunos, bem como de todas as discussões levantadas ao longo da intervenção. 


\section{Avaliação dos resultados}

Perante a necessidade de se trabalhar temáticas tão importantes para a formação crítica dos alunos em sala de aula, como a influência da mídia na "instituição do corpo perfeito" e a exposição exagerada nas redes sociais, acreditamos que, por meio dessa intervenção, foi possível proporcionar o entendimento da necessidade de se ter um olhar crítico sobre os textos que chegam até nós pelos diversos veículos de comunicação. Durante as discussões dos textos, procuramos ressaltar a importância de se analisar fatores como: locutor, veículo, destinatário, objetivo comunicativo, a fim de demonstrar que tais fatores corroboram fortemente para a construção do sentido de um texto.

Buscamos trabalhar com gêneros que interessassem aos alunos, como reportagens sobre temas interessantes, mito, tirinha, a fim de aproximar o mundo do aluno do mundo da escola.

No geral, os alunos foram bem receptivos e participativos nas discussões sobre os textos e nas atividades e demonstraram, pelo menos uma boa parte da turma, terem conseguido entender a importância de se ter um posicionamento crítico e consciente sobre a exposição e a valorização da autoimagem.

Acreditamos que o papel da escola é fazer com que os alunos percebam-se inseridos no uso real da língua e acreditamos que pudemos contribuir para a construção de leitores mais críticos, ainda que reconheçamos que nossa intervenção represente uma semente de um trabalho que deve ter caráter contínuo ao longo de toda a trajetória escolar.

\section{Considerações finais}

Ao longo do planejamento e da elaboração das atividades da intervenção didática, pudemos refletir sobre o pouco espaço oferecido à Cultura Clássica na sala de aula, mostrando que textos da Antiguidade têm muito de contemporâneo e que nós temos muito da Antiguidade. Nesse sentido, a partir de um mito, que trazia a temática a ser trabalhada ao longo da intervenção didática, foi possível trabalhar com diversos gêneros e envolver os alunos desde o começo.

Através da metodologia adotada, pudemos verificar o conhecimento que os alunos já tinham tanto sobre os gêneros selecionados como pela temática de cada um deles. O formato das aulas exigia um envolvimento dos alunos, uma vez que elas desenvolveram-se com base em leituras e nós 
acreditamos que pelo tema e pelos gêneros escolhidos, os alunos sentiram-se convidados a participarem, demonstrando que podem sim ler um texto de forma mais crítica.

Desse modo, concluímos que os alunos, em sua maior parte, conseguiram perceber que não podemos ser ingênuos e passivos na recepção de informações, estejamos onde estivermos, pois um texto é veiculado por alguém que tem um propósito e o onde é veiculado também exerce influência sobre o seu sentido.

\section{Referências}

BRASIL. Parâmetros Curriculares Nacionais: Ensino Fundamental. Brasília: MEC/ Semtec, 2002.

FORTES, F.S.; MIOTTI, C.M. Cultura Clássica e Ensino: uma reflexão sobre a presença dos gregos e latinos na escola. Organon, Porto Alegre, v.29, n.56, p. 153-173, jan/jun. 2014.

KLEIMAN, Angela. Oficina de leitura. Teoria e Prática. 15. ed. Campinas: Pontes Editores, 2013.

$\mathrm{KOCH}$, Ingedore Villaça; ELIAS, Vanda Maria. Ler e compreender: os sentidos do texto. 3. ed. São Paulo: Contexto, 2014.

\section{Anexo I}

Praticando...

Exercícios sobre o mito "Eco e Narciso" e sobre a reportagem "A hora das estrelas"

1. Quem foi Narciso? Conte, resumidamente, sua história.

2. Por qual motivo a deusa Juno castigou Eco? Qual foi o castigo?

3. Com base na leitura dos textos "Eco e Narciso" e "Narcisismo: a hora das Estrelas", 
responda:

4. Explique como a paixão de Narciso por si mesmo se relaciona com a ideia de imagem que temos de nós mesmos nos dias de hoje?

5. O psicanalista Sigmund Freud criou o termo Narcisismo, inspirado no mito de Narciso, para se referir ao distúrbio que se caracteriza como o enorme apego a própria imagem, além de um egoísmo exagerado. Você se considera uma pessoa narcisista? Por quê?

6. Com relação ao uso das redes sociais como o Facebook e o Instagram, dê a sua opinião: as redes sociais podem ajudar a "criar" cada vez mais jovens narcisistas? Por quê?

Anexo II

Praticando...

Do reflexo no lago ao reflexo nas lentes das câmeras...

1. Com base na reportagem "As formas absurdas de morrer ao fazer um 'selfie", diga em que consiste a campanha criada pelo governo russo?

2. No texto "As formas absurdas de morrer ao fazer um 'selfie",, das cinco situações de perigo em que as selfies tiveram consequências fatais, escolha a que você achou mais absurda e comente sobre essa situação. 
3. O que você acha das selfies? Você faz uso delas no seu dia a dia?

4. Você se arriscaria para tirar fotos inusitadas, como nos casos que vimos? Por quê?

5. Qual a semelhança entre as mortes ocasionadas por selfies e a morte de Narciso, personagem do mito "Eco e Narciso"? 